TABLE V-Numbers (percentages) of elderly people in the various age groups who died in 1976, 1980, and 1984 and who spent 30 days or more, 90 days or more, or all of their final year of life in hospital

\begin{tabular}{|c|c|c|c|c|c|c|c|c|c|}
\hline \multirow{2}{*}{$\begin{array}{c}\text { Age group } \\
\text { (years) }\end{array}$} & \multicolumn{3}{|c|}{$\geqslant 30$ Days } & \multicolumn{3}{|c|}{$\geqslant 90$ Days } & \multicolumn{3}{|c|}{$\geqslant 1$ Year } \\
\hline & 1976 & 1980 & 1984 & 1976 & 1980 & 1984 & 1976 & 1980 & 1984 \\
\hline $65-69$ & $433 / 2036(21 \cdot 3)$ & $404 / 1984(20 \cdot 4)$ & $322 / 1531(21 \cdot 0)$ & $79 / 2036 \quad(3.9)$ & $100 / 1984(5 \cdot 0)$ & $61 / 1531 \quad(4 \cdot 0)$ & $5 / 2036(0 \cdot 2)$ & $8 / 1984(0 \cdot 4)$ & $6 / 1531(0 \cdot 4)$ \\
\hline $70-74$ & $587 / 2675(21 \cdot 9)$ & $574 / 2615(21.9)$ & $597 / 2653(22 \cdot 5)$ & $155 / 2675 \quad(5.8)$ & $142 / 2615 \quad(5.4)$ & $124 / 2653(4 \cdot 7)$ & $24 / 2675(0.9)$ & $27 / 2615(1 \cdot 0)$ & $19 / 2653(0 \cdot 7)$ \\
\hline $75-79$ & $697 / 2759(25 \cdot 3)$ & $755 / 3016(25 \cdot 0)$ & $783 / 3008(26 \cdot 0)$ & $195 / 2759(7 \cdot 1)$ & $211 / 3016(7 \cdot 0)$ & $214 / 3008(7 \cdot 1)$ & $27 / 2759(1.0)$ & $37 / 3016(1 \cdot 2)$ & $32 / 3008(1 \cdot 1)$ \\
\hline $80-84$ & $667 / 2640(25 \cdot 3)$ & $713 / 2789(25 \cdot 6)$ & $794 / 2875(27 \cdot 6)$ & $261 / 2642(9.9)$ & $255 / 2789(9 \cdot 1)$ & $254 / 2875(8.8)$ & $45 / 2640(1 \cdot 7)$ & $54 / 2789(1.9)$ & $56 / 2875(1.9)$ \\
\hline $85-89$ & $487 / 2022(24 \cdot 1)$ & $566 / 2082(27 \cdot 2)$ & $610 / 2008(30 \cdot 4)$ & $191 / 2022(9 \cdot 4)$ & $225 / 2082(10 \cdot 8)$ & $228 / 2008(11 \cdot 3)$ & $44 / 2022(2 \cdot 2)$ & $65 / 2082(3 \cdot 1)$ & $59 / 2008(2 \cdot 9)$ \\
\hline$\geqslant 90$ & $337 / 1389(24 \cdot 3)$ & $382 / 1403(27 \cdot 2)$ & $394 / 1478(26 \cdot 7)$ & $161 / 1389(11 \cdot 6)$ & $188 / 1403(13 \cdot 4)$ & $174 / 1478(11 \cdot 8)$ & $64 / 1389(4 \cdot 6)$ & $65 / 1403(4 \cdot 6)$ & $66 / 1478(4 \cdot 5)$ \\
\hline
\end{tabular}

least mobile of all age groups. Inward migration of people aged 60 and over to the counties covered by the Oxford region was only $2 \%$ in $1985 .^{7}$ Nevertheless, conceivably the terminally ill have different migration patterns, possibly including moving to live with relatives.

The Oxford record linkage study collects data only from NHS hospitals. Data on other facilities used in the care of the elderly were not available. The recent increase in numbers of residential and nursing homes for the elderly may have taken some of the role of residential care from NHS hospitals, and our findings should be interpreted in the light of this.

The proportion of the population admitted to hospital in the year preceding death increased over time in all age groups. The increase was consistent with the general increase in admission rates reported elsewhere. ${ }^{8}$ The finding that advanced age at death was associated with lower rates of prior hospital admission was unexpected but there are several possible explanations. Firstly, doctors may be unwilling to admit very old people to hospital because medical and surgical intervention may be considered inappropriate. Secondly, as noted above, the very elderly may already be in residential care other than hospital. For example, we estimate that $11 \%$ of people who died at age 90 and over in 1985 in our study were resident in part III accommodation before hospital admission compared with $0 \cdot 4 \%$ of the $65-69$ year age group. The very elderly may therefore not have been in need of hospital admission solely for residential or nursing care. Thirdly, people who live to a very old age may be basically healthy until shortly before death.

The increase over time in admission rates was, in general, counterbalanced by a decline in the total time spent in hospital by those admitted. Mean total days in hospital based on all deaths in the population did not increase over time, and the median total days in hospital increased by only about three days between 1976 and 1985. The proportion of people who spent 30 days or more in hospital did not change appreciably.

Stout and Crawford in Belfast found that duration of terminal dependency among long stay geriatric patients had increased. ${ }^{9}$ Our study design contrasts with theirs in important respects. The Belfast study was confined to patients with lengths of stay of 90 days or longer; in our study these made up only about $4 \%$ of people aged $65-74$ and $10 \%$ of people aged 85 and over. Our study relates lengths of hospital care to a total, defined population of the elderly who died, including those with short as well as long stays and including those who died without admission to hospital at all. In conclusion, our population based findings show that the gain in life expectancy between 1976 and 1985 was not at the expense of any substantial increase in time spent in hospital in the year before death.

The unit of clinical epidemiology is funded by the Department of Health and is part of the department of public health and primary care, University of Oxford.

Office of Population Censuses and Surveys. Mortality Statistics 1985. London: HMSO, 1987:25

2 Wilkins R, Urb M, Adams OB. Health expectancy in Canada, late 1970 demographic, regional and social dimensions. Am f Public Health 1983;73 1073-80.

3 Colvez A, Blanchet M. Disability trends in the United States population 1966 76: analysis of reported causes. Am f Public Health 1981;71:464-71.

4 Gruenberg EM. The failures of success. Milbank Memorial Fund Quarterly 1977;55:3-24.

5 Katz S, Branch LG, Branson MH, Papsidero JA, Beck JC, Greer DS. Active life expectancy. N Engl f Med 1983;309:1218-24.

6 Fries JF. Aging, natural death, and the compression of morbidity. $\checkmark$ Engl Y Med 1980;303:130-5.

7 Office of Population Censuses and Surveys. Population and vital statistics 198 London: HMSO, 1987:86-9.

8 Goldacre MJ, Simmons H, Henderson J, Gill LE. Trends in episode based and person based rates of admission to hospital in the Oxford record linkage study area. Br Med f 1988;296:583-5.

9 Stout RW, Crawford V. Active-life expectancy and terminal dependency: trends in long-term geriatric care over 33 years. Lancet 1988;i:281-3.

(Accepted 17 April 1990)

\title{
Hyperosmolality related to propylene glycol in an infant treated with enoximone infusion
}

\section{Cardiac Intensive Care Unit, Hospital for Sick Children, Great Ormond Street, London WC1N 3JH I Huggon, MRCP, senior house officer \\ I James, FCANAES, consultant D Macrae, FCANAES, consultant}

\section{Correspondence to:}

Dr I Huggon, Department of Paediatric Cardiology, Guy's Hospital, London SE1 9RT.

BrMed f 1990;301:19-20

\section{Huggon, I James, D Macrae}

We report on an infant with heart failure in whom a potentially dangerous accumulation of propylene glycol occurred during enoximone infusion.

\section{Case report}

A $3.4 \mathrm{~kg}$ male infant could not be weaned from ventilatory support after open heart surgery for an atrioventricular septal defect, despite reoperation for a residual defect. His cardiac output remained unsatisfactory even with inotropic support from dopamine and dobutamine, after reduction of afterload with intravenous glyceryl trinitrate and captopril, restriction of fluids, and diuretics. Enoximone infusion $(20 \mu \mathrm{g} / \mathrm{kg} / \mathrm{min})$ was begun on the 28 th postoperative day. His serum osmolality, measured daily because of the diuretic treatment, rose from $304 \mathrm{mmol} / \mathrm{kg}$ before the start of the infusion to $385 \mathrm{mmol} / \mathrm{kg}$ by the fourth day of treatment. There was no corresponding rise in serum electrolyte or glucose concentrations. Urea and creatinine concentrations were $12.6 \mathrm{mmol} / \mathrm{l}$ and $43 \mu \mathrm{mol} / 1$ respectively.

The fluid restriction was eased until it became clear that the rise in osmolality was due not to dehydration but to the presence of additional dissolved material. A review of his drug treatment indicated that propylene glycol was the probable cause as it is a constituent of both glyceryl trinitrate and enoximone infusions. At the rates administered enoximone accounted for most of the propylene glycol infused $(2.4 \mathrm{mg} / \mathrm{kg} / \mathrm{min}$ compared with $0.3 \mathrm{mg} / \mathrm{kg} / \mathrm{min}$ from the glyceryl trinitrate infusion). When enoximone was stopped the osmolality decreased to normal values over the next four 
days. Stopping glyceryl trinitrate did not result in any further fall in osmolality.

\section{Comment}

Enoximone is a phosphodiesterase 3 inhibitor that has beneficial effects on low cardiac output. ${ }^{1}$ The formulation we used (Perfan, Merrell Dow) contains propylene glycol $41 \cdot 3 \% \mathrm{wt} / \mathrm{vol}$. Propylene glycol is present in many drug preparations but rarely causes harmful effects. Adverse systemic accumulation has, however, been reported with topical silver sulphadiazine, ${ }^{2}$ intravenous glyceryl trinitrate, ${ }^{3}$ and multivitamin preparations. ${ }^{4}$ Toxicity caused by propylene glycol may be manifested by hyperosmolality, lactic acidosis, haemolysis and haemoglobinuria, skin irritation, and deafness and other neurological disturbances. As propylene glycol distributes into both intracellular and extracellular compartments the hyperosmolar state associated with it is well tolerated.

We did not directly measure propylene glycol concentrations in our patient, but estimation based on the osmolal gap $^{245}$ (the difference between calculated osmolality and measured osmolality) gave a value of about $10 \mathrm{~g} / \mathrm{l}$, which has been associated with toxicity in previous reports but did not adversely affect our patient.

After the enoximone infusion was stopped the osmolality fell gradually towards normal values, consistent with an elimination half life of 41 hours. This exceeds the mean half life of five hours quoted for adults ${ }^{3}$ and 16.9 hours for neonates ${ }^{2}$ and may have been influenced by the continued administration of some propylene glycol with the glyceryl trinitrate. Up to $45 \%$ of propylene glycol is excreted in the urine, and poor renal function has an important effect on the accumulation of propylene glycol and the osmolal gap. ${ }^{3}$ Impaired renal function, indicated by reduced elimination of gentamicin, may have contributed to the accumulation seen here.

As infusion of enoximone at a maximum dose delivers more propylene glycol to the patient than other drug infusions containing this compound the risk of adverse effects may be correspondingly greater with enoximone. As renal impairment often accompanies cardiac failure and may promote the accumulation of propylene glycol we recommend that particular care should be taken to use the minimum effective dose of enoximone, especially in infants. Estimations of serum electrolyte and urea concentrations and osmolality permit calculation of the osmolal gap, changes in which may be used as a non-specific indicator of changes in plasma concentrations of propylene glycol.

1 Gonzales $M$, Desager J-P, Jaquemart J-L, Chenu P, Muller T, Installe E. Efficacy of enoximone in the management of refractory low output states following cardiac surgery. Fournal of Cardiothoracic Anesthesia 1988;2:409-18.

2 Fligner CL, Jack R, Twiggs GA, Raisys VA. Hyperosmolality induced by propylene glycol. A complication of silver sulfadiazine therapy. $7 A M A$ 1985;253:1606-9.

3 Demey HE, Daelmans RA, Verpooten GA, et al. Propylene glycol-induced side effects during intravenous nitroglycerin therapy. Intensive Care Med 1988:14:221-6.

4 Glasgow AM, Boeckx RL, Miller MK, MacDonald MG, August GP. Hyperosmolality in small infants due to propylene glycol. Pediatrics $1983 ; 72$ :

5 Hall AH, Bronstein AC, Smolinske SC, et al. Propylene glycol plasma level. Pediatrics 1986;76:654.

(Accepted 30 March 1990)

\section{Use of histoacryl tissue adhesive to manage an avulsed tooth}

\section{J McCabe}

\section{Accident and Emergency Department, Northwick Park Hospital, Middlesex HA1 3UJ \\ M J McCabe, FRCSED, registrar}

Correspondence to: Accident and Emergency Department, Cardiff Royal Infirmary, Cardiff CF2 1SZ.

BrMed f 1990;301:20-1
Avulsed teeth are not uncommon and may occur in sport, assaults, and domestic violence. Successful reimplantation of an avulsed tooth depends on its rapid reinsertion into the socket and on maintaining its position by splinting before definitive treatment. Many patients present to accident and emergency departments rather than to their dental practitioners, especially at nights and weekends. ${ }^{1}$ A simple splinting technique that can be used by senior house officers in accident departments is needed.

\section{Case report}

A 20 year old man presented to the accident department within 30 minutes of receiving a blow to the mouth with a hockey stick. The upper left first incisor had been avulsed and the upper left second incisor and upper right first incisor had fractured at the level of the gum. There were no fractures of the facial bones or dental fragments in the lips. The adjacent teeth were fractured at gum level so metal foil could not be used to splint the avulsed tooth and an alternative method was needed.

The tooth was replaced into the socket and maintained in position by applying histoacryl tissue adhesive (Cyanamid) from the enamel to the gingiva (figure). The adhesive was not allowed to encroach into the socket. A course of ampicillin was prescribed and a tetanus toxoid booster given. The patient was reviewed by his local dental practitioner two days later: the reimplanted tooth had not loosened, and root treatment was performed. Review at six months showed apical resorption, but the patient was asymptomatic. The root of the upper right first incisor had to be extracted.

\section{Comment}

Histoacryl tissue adhesive has been used successfully for a variety of purposes, including closing skin lacerations $s^{2}$ and securing skin grafts. It is biodegradable but remains until the wound has healed well; it is also non-toxic to epithelial tissues. ${ }^{2}$ After an avulsed tooth has been reinserted into the socket it must be adequately splinted ${ }^{3}$; metal foil splints, composite and orthodontic wire, suturing, and vacuum formed splints can be used. ${ }^{4}$ Each technique has advantages and problems. ${ }^{45}$

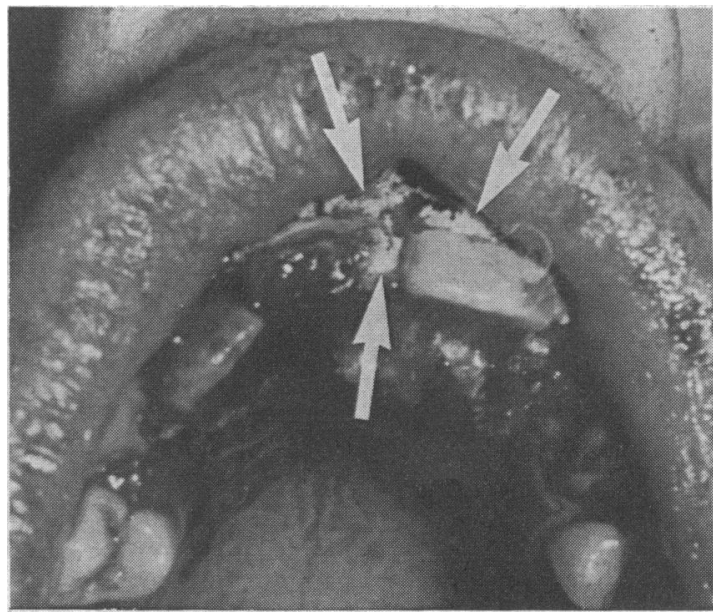

Reimplanted upper left first incisor; arrows show position of tissu adhesive 